\title{
The association of binge eating and neighbourhood fast-food restaurant availability on diet and weight status
}

\author{
Tracey Ledoux ${ }^{1, *}$, Heather Adamus-Leach ${ }^{1}$, Daniel P O'Connor ${ }^{1}$, Scherezade Mama ${ }^{1}$ \\ and Rebecca E Lee ${ }^{2}$ \\ ${ }^{1}$ Texas Obesity Research Center, University of Houston, 104 Garrison Gym, 3855 Holman Street, Houston, TX \\ 77204-6015, USA: ${ }^{2}$ College of Nursing and Health Innovation, Arizona State University, Phoenix, AZ, USA
}

Submitted 19 November 2012: Final revision received 9 September 2013: Accepted 10 December 2013: First published online 24 January 2014

\begin{abstract}
Objective: Fast-food restaurants (FFR) are prevalent. Binge eating is common among overweight and obese women. For women prone to binge eating, neighbourhood FFR availability (i.e. the neighbourhood around one's home) may promote poor diet and overweight/obesity. The present study tested the effects of binge eating and neighbourhood FFR availability on diet (fat and total energy intake) and BMI among African American and Hispanic/Latino women. Design: All measures represent baseline data from the Health is Power randomized clinical trial. The numbers of FFR in participants' neighbourhoods were counted and dichotomized ( 0 or $\geq 1$ neighbourhood FFR). Participants completed measures of binge eating status and diet. Weight and height were measured and BMI calculated. 2 (binge eating status) $\times 2$ (neighbourhood FFR availability) ANCOVA tested effects on diet and BMI while controlling for demographics.

Setting: Houston and Austin, TX, USA.

Subjects: African American and Hispanic/Latino women aged 25-60 years.

Results: Of the total sample ( $n$ 162), $48 \%$ had 1-15 neighbourhood FFR and $29 \%$ were binge eaters. There was an interaction effect on BMI $(P=0.05)$. Binge eaters with $\geq 1$ neighbourhood FFR had higher BMI than non-binge eaters or binge eaters with no neighbourhood FFR. There were no significant interactions or neighbourhood FFR main effects on total energy or fat intake $(P>0.05)$. A main effect of binge eating showed that binge eaters consumed more total energy $(P=0 \cdot 005)$ and fat $(P=0 \cdot 005)$ than non-binge eaters.

Conclusions: Binge eaters represented a substantial proportion of this predominantly overweight and obese sample of African American and Hispanic/ Latino women. The association between neighbourhood FFR availability and weight status is complicated by binge eating status, which is related to diet.
\end{abstract}

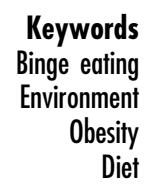

African American (AA) and Hispanic/Latino (HL) adults suffer from higher rates of heart disease ${ }^{(1)}$, obesity ${ }^{(2)}$ and diabetes $^{(3)}$ than their Caucasian peers. A diet high in fat ( $\geq 30 \%$ of total energy from fat) and excess energy is associated with chronic diseases and obesity ${ }^{(4-6)}$, and large proportions of AA and HL adults consume excess energy from $\mathrm{fat}^{(\mathrm{(7)}}$. Identifying determinants of diet and obesity among AA and HL women may provide intervention targets for reducing obesity among these high-risk groups.

Ecological models posit that health behaviours such as dietary intake are influenced by individual-, sociocultural-, organizational-, community- and policy-level factors ${ }^{(8-11)}$. The number and type of eating establishments available in one's environment represent community-level factors that influence behaviour. Fast-food restaurants (FFR) are widely available, particularly among low-income and minority neighbourhoods ${ }^{(12-15)}$, and serve mostly high-fat, energydense, nutrient-poor foods ${ }^{(16,17)}$. Frequent fast-food consumption has been related to higher fat intake ${ }^{(12,18-20)}$ and poor health ${ }^{(21-24)}$. Availability of FFR in one's residential neighbourhood increases the likelihood of consuming fast foods ${ }^{(23,25,26)}$, having poor diet quality ${ }^{(12,27)}$ and being obese $^{(23,24,28-30)}$. However, not all individuals within a given environment will have a poor diet or become obese; some studies did not find an association between residential neighbourhood availability of FFR and $\operatorname{diet}^{(31-33)}$ or obesity $^{(32)}$, while some found the inverse to be true (greater neighbourhood FFR availability associated with lower BMI) ${ }^{(34)}$. Identifying qualities or individual factors that make some individuals more likely to become obese in an obesogenic environment where FFR are prevalent 
will allow the development of targeted policies and interventions with greater effectiveness.

The relationship between neighbourhood FFR availability and fast-food consumption appears to be moderated by sensitivity to external reward cues and sense of control over the environment ${ }^{(35,36)}$. Neighbourhood FFR availability and fast-food consumption were more positively related among those who were sensitive to external reward cues ${ }^{(36)}$ and had a higher sense of control over their environment ${ }^{(35)}$. Sensitivity to reward cues and low sense of control are qualities of binge eaters ${ }^{(37,38)}$. Binge eating refers to overeating with loss of control and associated feelings of guilt and shame ${ }^{(37)}$, and it is commonly reported by $15-20 \%$ of non-clinical AA and HL women ${ }^{(39)}$. External cues trigger impulsive binge eating episodes via their effects on reward and motivation centres of the brain ${ }^{(38,40-42)}$. It is possible that FFR serve as binge triggers for those with a tendency to binge eat; therefore for bingers, greater FFR exposure may trigger more frequent binge episodes. In addition, FFR provide highly palatable, energy-dense foods to customers very quickly and conveniently, making impulsive binge eating very easy and convenient.

Binge eating is a shameful and secret behaviour for those who struggle with it ${ }^{(43)}$. Binge eating is far more likely to occur at home ${ }^{(43-45)}$, in the evening ${ }^{(46)}$, on weekends $^{(46)}$ and when alone ${ }^{(43-45,47)}$. In one study, $72 \%$ of participants reported that going home after work or school was a binge trigger ${ }^{(45)}$. In another study, one-third of those with a tendency towards binge eating did so in the $\operatorname{car}^{(48)}$. These common binge eating characteristics suggest that food cues in the neighbourhood environment around one's home may be more salient in influencing diet and weight status for binge eaters than non-binge eaters.

The aims of the current study were to determine: (i) whether binge eating moderated the association between neighbourhood FFR availability and diet (i.e. total energy intake and percentage of total energy intake from fat); and (ii) whether binge eating moderated the association between neighbourhood FFR availability and BMI. Neighbourhood FFR availability was operationally defined as an $800 \mathrm{~m}(0.5$ mile $)$ radius around each participant's residence. We hypothesized that: (i) the relationship between neighbourhood FFR availability and diet would be positive and stronger among bingers than non-bingers; and (ii) the relationship between neighbourhood FFR availability and BMI would be positive and stronger among bingers than non-bingers.

\section{Method}

\section{Design and sample}

A unique descriptive cross-sectional study was conducted using baseline data from a larger longitudinal, multisite, randomized controlled trial called Health is Power ${ }^{(49-51)}$.
The purpose of Health is Power was to test a transcultural, community-based intervention to increase physical activity and improve dietary habits among AA and $\mathrm{HL}$ women from Houston and Austin, TX, USA ${ }^{(49,50,52)}$. Four hundred and ten apparently healthy AA and HL women (311 in Houston and ninety-nine in Austin) were recruited for Health is Power. In Houston, $84.6 \%$ identified as $\mathrm{AA}$ and $15.4 \%$ identified as $\mathrm{HL}$; all women in Austin identified as HL. The study sample and design have been described previously ${ }^{(49,50)}$. However, briefly, an uneven sample design was used because it was determined that a smaller comparison group would provide enough power to determine effects; and in year 2 , the funders cut the budget by over $25 \%$ prematurely cutting off recruitment in the second site (Austin). Women who were recruited completed baseline questionnaires including the Binge Eating Scale (BES) and a demographic survey and had researchers assess their residential neighbourhoods. At baseline, these women were provided a run-in packet that included the National Cancer Institute's Dietary History Questionnaire (DHQ). The run-in packet method was used to encourage early withdrawal by those who are less motivated and likely to drop out later in the intervention. Women were randomly assigned to the intervention only when the run-in packet was returned.

\section{Procedure}

\section{Individual data collection}

The study protocol was approved by the University of Houston's Committee for the Protection of Human Subjects before recruitment began. Women were recruited via community advertisements throughout Houston and Austin to participate in a health promotion intervention. Interested participants contacted study staff, who conducted a telephone-administered screening ${ }^{(50)}$. Physically inactive women between 25 and 60 years old were invited to give written consent and complete a baseline (T1) health assessment ${ }^{(50)}$. At the $\mathrm{T} 1$ assessment, participants completed an interviewer-administered questionnaire, anthropometric measures of BMI and body fat, and were given a take-home packet to complete prior to the next meeting (approximately one week later). The packet contained more detailed questionnaires not found in the interviewer-administered questionnaire, including the $\mathrm{DHQ}^{(49,50,52-57)}$.

\section{Environmental data collection}

To complete environmental assessments, neighbourhoods were first mapped using Geographical Information Systems (GIS) technology. Participants' addresses were geocoded, and a participant's neighbourhood was defined as the area within an $800 \mathrm{~m}(0.5$ mile) radius circumscribed around her home. Defining the neighbourhood as the area within the boundaries of the circle has several advantages that 
have been discussed exhaustively in previous work by the authors $^{(49,58)}$. Advantages of using a $800 \mathrm{~m}$ circular buffer are: (i) it captures all area to which a resident may be exposed on a daily basis during both foot and automobile travels; (ii) the straight-line distance allows for capture of distance travelled on footpaths and other 'short cut' routes that may not be captured by using a street network strategy; and (iii) it may reduce the effect of spatial correlation that arises from using census boundaries where points near the boundary of the census area are influenced by factors in adjacent census areas. Next, an Intersect command in ArcGIS was used to combine the neighbourhood buffers and street centrelines to create a buffer streets layer. Field assessors completed an interactive training using standardized PowerPoint training slides with pictures and operational definitions over the course of half a day and completed at least $4 \mathrm{~h}$ of mentored field training. Environmental assessment procedures have been previously described in detail ${ }^{(49,51,56,58-60)}$. Assessors completed field assessments in teams of two and took GIS maps to guide them and ensure that all street segments were assessed. The Goods and Services Inventory (GASI) is an in-person, street-level neighbourhood audit measurement tool. Assessment teams of two people walked the segmented areas and counted the number of various types of goods and services (e.g. FFR, pawn shops) within the $800 \mathrm{~m}$ buffer using the GASI according to operational definitions $^{(49,51,56,58-60)}$.

\section{Individual measures}

\section{Demographics}

The Maternal and Infant Health Assessment (MIHA) was used to measure the participant's education, parents' education and income. The MIHA is modelled on the Centers for Disease Control and Prevention's Pregnancy Risk Assessment Monitoring System (PRAMS), and items have been used with ethnically diverse samples and socio-economic status categories ${ }^{(61)}$.

\section{Binge Eating Scale}

The BES is a self-report questionnaire that measures binge eating symptoms but does not provide a clinical diagnosis of binge eating disorder ${ }^{(62)}$. The BES has sixteen groups of items that describe both the behavioural manifestations and feelings/cognitions surrounding a binge episode ${ }^{(62)}$. Participants are asked to choose one statement in each group of items that best describes the way they feel; each item in a group of items represents a rating from 0 to $3^{(62)}$. Adding the responses to each question provides an overall score of binge eating, with a higher score indicating greater severity of binge eating symptoms ${ }^{(62-64)}$. Studies in samples of AA and white women have demonstrated strong internal consistency, with values of $\alpha$ ranging between $0 \cdot 88$ and $0 \cdot 91^{(65,66)}$. Studies in samples of Hispanic, AA and white women showed that the BES is a widely used valid measure of binge eating symptomatology ${ }^{(67-70)}$. Based on the criteria developed by Marcus et $a l .{ }^{(71)}$, participants were categorized into groups of non-bingers (BES score <18) and bingers (BES score $\geq 18$ ).

\section{Diet History Questionnaire}

The National Cancer Institute's $\mathrm{DHQ}^{(72,73)}$ measured usual consumption of 124 food items over the past 12 months. The DHQ has adequate validity $\left(r_{\mathrm{s}}=0.49\right.$ in men, $0 \cdot 48$ in women) and reliability $(r=0 \cdot 70$ to $0 \cdot 85)$ in large diverse samples when compared with other established and validated $\mathrm{FFQ}^{(73,74)}$. It has been widely used to assess diet among $\mathrm{AA}$ and $\mathrm{HL}$ populations since its development (e.g. references 75-78). Total energy intake and the percentage of total energy intake from fat were calculated for the present study.

\section{Environmental measures}

The Goods and Services Inventory

Trained field assessors used the GASI ${ }^{(79,80)}$ ( (C) 2010) to tabulate all goods and services available within an $800 \mathrm{~m}$ ( 0.5 mile) radius of participants' home addresses. The twenty types of goods and services included on the GASI are: (i) table-service restaurants, (ii) FFR, (iii) other types of restaurants, (iv) supermarkets, (v) grocery stores, (vi) gas stations/convenience stores, (vii) pharmacies, (viii) banks/credit unions, (ix) pawn shops, (x) cheque-cashing stores, (xi) liquor stores, (xii) tobacco stores, (xiii) bars or nightclubs, (xiv) adult video stores, (xv) sexrelated businesses/adult sex clubs/strip bars, (xvi) places of worship, (xvii) salons/barbers/beauty shops, (xviii) schools, (xix) day cares and (xx) libraries, within a particular geographically defined area. The GASI has been validated and showed good inter-rater reliability in multiple cities $^{(60)}$. The present study used only the items assessing FFR, as most foods served in these establishments contribute to a high-fat diet. An FFR was defined as a restaurant in which 'Orders and food pick-up completed at the counter or from a car. There is no table service'. This includes restaurants that produce solely 'carry-out' food, and may or may not have a 'drive through'. FFR did not include other types of table-service restaurants or convenience store foods.

\section{Statistical analyses}

Data were screened for data-entry errors or outliers before initiating data analysis. The data were not weighted individually, as would be done in a survey sample with probability of selection, since this was not a probability sample. A cluster command was not used because there were only two clusters, which creates a fixed difference not an intercluster variance. Including site as a covariate accounted for that fixed difference. Participants who reported eating $<3347 \mathrm{~kJ} / \mathrm{d}(<800 \mathrm{kcal} / \mathrm{d})$ were 
considered outliers and excluded from analyses. After exclusions were made, a sample of 170 remained for study analyses. Preliminary data inspection confirmed assumptions of normality, homogeneity of variance, linearity and homogeneity of regression slopes. A series of 2 (bingers $v$. non-bingers) $\times 2$ (0 neighbourhood FFR $v$. $\geq 1$ neighbourhood FFR) ANCOVA with age, race and city of recruitment (i.e. Austin or Houston) serving as covariates were conducted to examine main and interaction effects on BMI, energy intake and fat intake. Analyses were performed using the statistical software package IBM SPSS Statistics 20. The level of significance was set at $P<0 \cdot 05$.

\section{Results}

Four hundred and ten women completed baseline data for the parent study. Two hundred and five participants did not return the run-in packets which included the dietary data and some were excluded because they reported consuming $<3347 \mathrm{~kJ} / \mathrm{d}(<800 \mathrm{kcal} / \mathrm{d} ; n$ 17). There were no differences between those not included in the final data set (under-reporters or those without dietary data) and those who were on age, BMI, BES score or neighbourhood FFR availability. AA women were more likely to not report or under-report dietary intake than HL women $(P=0 \cdot 03)$. Of the remaining 188 participants, 170 provided complete data on all study variables and were included in ANCOVA.

Of the total sample in the study, 115 participants (67.6\%) were non-bingers (scored $<18$ on the BES) and fifty-five $(32 \cdot 4 \%)$ were bingers (scored $\geq 18$ on the BES). Ninety-five participants had no FFR in their neighbourhood and seventy-five had $\geq 1$ neighbourhood FFR (range: 1-15). Fifty-five per cent ( $n$ 89) of those who provided data on income had incomes $>401 \%$ of the federal poverty level, 44\% ( $n$ 70) had incomes 100-400\% of the federal poverty level, and $1 \%(n 2)$ had incomes below the federal poverty level. See Table 1 for means and standard deviations on continuous variables related to sample characteristics.

\section{BMI}

After adjusting for age, city and race, there was a main effect of binge eating on $\mathrm{BMI}(F(1,163)=5 \cdot 53, P=0 \cdot 02)$, with a small effect size (partial $\eta^{2}=0 \cdot 03$ ), but there was no significant main effect of neighbourhood FFR availability $(F(1,163)=0 \cdot 105, P=0 \cdot 75)$. After adjusting for age, city and race, there was a marginally significant interaction effect of binge eating and neighbourhood FFR availability on BMI $(F(1,163)=3 \cdot 61, P=0 \cdot 06)$, with a small effect size (partial $\eta^{2}=0 \cdot 002$ ). Binge eaters with $\geq 1 \mathrm{FFR}$ in their neighbourhood had higher BMI than binge eaters with 0 FFR in their neighbourhood, but non-bingers with $\geq 1$ FFR in their neighbourhood had lower BMI than non-bingers with 0 FFR in their neighbourhood (see Fig. 1 and Table 2).

\section{Total energy intake}

After adjusting for age, race and city, there was a main effect of binge eating on total energy intake $(F(1,164)=$ $5 \cdot 50, P=0 \cdot 02$ ), with a small effect size (partial $\eta^{2}=0 \cdot 03$ ). Bingers had higher total energy intake than non-bingers (see Table 2). There was no significant main effect of neighbourhood FFR availability $(F(1,164)=1 \cdot 68, P=0 \cdot 20)$ and no significant interaction effect on total energy intake $(F(1,164)=0 \cdot 73, P=0 \cdot 39)$.

\section{Percentage of total energy intake from fat}

After adjusting for age, race and city, there was a main effect of binge eating on percentage of total energy intake from fat $(F(1,164)=5 \cdot 78, P=0 \cdot 02)$, with a small effect size (partial $\eta^{2}=0 \cdot 03$ ). Bingers consumed a higher percentage of their total energy intake from fat than non-bingers (see Table 2). There was no significant main effect of neighbourhood FFR availability $(F(1,164)=0 \cdot 28, P=0 \cdot 60)$ and no significant interaction effect on percentage of total energy intake from fat $(F(1,164)=1 \cdot 05, P=0 \cdot 31)$.

\section{Discussion}

The purpose of the present study was to determine whether there was a combined effect of neighbourhood FFR availability and binge eating status on BMI and diet

Table 1 Characteristics of the study sample: African American (AA) and Hispanic/Latino (HL) women aged 25-60 years, Houston and Austin, TX, USA

\begin{tabular}{|c|c|c|c|c|}
\hline & \multicolumn{2}{|c|}{$\begin{array}{l}\text { HL women } \\
\quad(n 67)\end{array}$} & \multicolumn{2}{|c|}{$\begin{array}{c}\text { AA women } \\
(n 103)\end{array}$} \\
\hline & Mean & SD & Mean & SD \\
\hline Age (years) & $46 \cdot 5$ & $9 \cdot 4$ & $45 \cdot 3$ & $9 \cdot 5$ \\
\hline $\mathrm{BMl}\left(\mathrm{kg} / \mathrm{m}^{2}\right)$ & $34 \cdot 61$ & $7 \cdot 3$ & $34 \cdot 17$ & $7 \cdot 5$ \\
\hline Total energy intake $(\mathrm{kJ} / \mathrm{d})$ & 8966 & 4071 & 8192 & 3167 \\
\hline Total energy intake $(\mathrm{kcal} / \mathrm{d})$ & 2143 & 973 & 1958 & 757 \\
\hline Total energy intake from fat (\%) & $37 \cdot 9$ & $5 \cdot 0$ & $36 \cdot 1$ & $7 \cdot 4$ \\
\hline BES score (range: $0-37$ ) & $15 \cdot 6$ & $9 \cdot 1$ & $12 \cdot 9$ & $7 \cdot 3$ \\
\hline No. of FFR in neighbourhood (range: $0-15$ ) & $1 \cdot 54$ & $2 \cdot 6$ & $1 \cdot 34$ & 1.0 \\
\hline
\end{tabular}

BES, Binge Eating Scale; FFR, fast-food restaurant. 


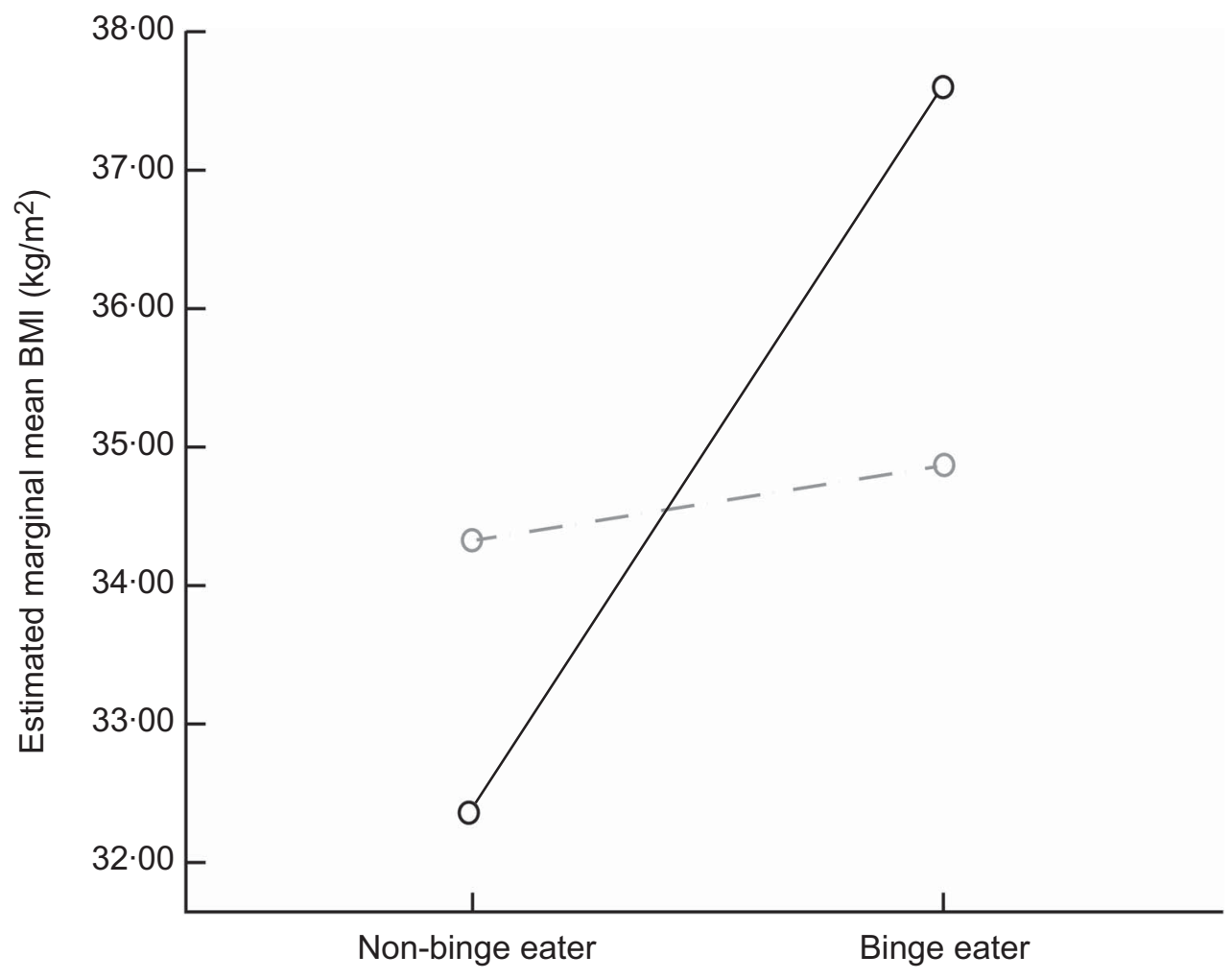

Binge eater status

Fig. 1 Interaction effect of binge eater status and neighbourhood fast-food restaurant (FFR) availability $(--\circ--, 0$ FFR; - _ $\geq 1$ FFR) on BMI among African American and Hispanic/Latino women aged 25-60 years, Houston and Austin, TX, USA. Covariates appearing in the model are evaluated at the following values: ethnicity (by identification) $=0.61$, study site $=1 \cdot 30$ and age (years) $=45 \cdot 7661$

Table 2 Group means and standard deviations of BMI, total energy intake and percentage of total energy intake from fat according to neighbourhood fast-food restaurant (FFR) availability and binge eating: African American and Hispanic/Latino women aged 25-60 years, Houston and Austin, TX, USA

\begin{tabular}{|c|c|c|c|c|c|c|c|c|}
\hline & \multicolumn{4}{|c|}{0 neighbourhood FFR } & \multicolumn{4}{|c|}{$\geq 1$ neighbourhood FFR } \\
\hline & \multicolumn{2}{|c|}{$\begin{array}{l}\text { Binge eaters } \\
\quad(n 30)\end{array}$} & \multicolumn{2}{|c|}{$\begin{array}{l}\text { Non-binge eaters } \\
(n \text { 65) }\end{array}$} & \multicolumn{2}{|c|}{$\begin{array}{l}\text { Binge eaters } \\
\quad(n 25)\end{array}$} & \multicolumn{2}{|c|}{$\begin{array}{l}\text { Non-binge eaters } \\
(n 50)\end{array}$} \\
\hline & Mean & SD & Mean & SD & Mean & SD & Mean & SD \\
\hline BMI $\left(\mathrm{kg} / \mathrm{m}^{2}\right)$ & $34 \cdot 82^{a}$ & $6 \cdot 8$ & $34 \cdot 43^{\mathrm{a}}$ & $7 \cdot 4$ & $37 \cdot 63^{b}$ & $7 \cdot 8$ & $32 \cdot 31^{c}$ & $7 \cdot 2$ \\
\hline Total energy intake $(\mathrm{kJ} / \mathrm{d})$ & $10366^{a}$ & 3840 & $7976^{b}$ & 3245 & $8714^{\mathrm{a}}$ & 3026 & $7963^{b}$ & 3710 \\
\hline Total energy intake $(\mathrm{kcal} / \mathrm{d})$ & $2477 \cdot 50^{a}$ & $917 \cdot 7$ & $1906 \cdot 32^{b}$ & $775 \cdot 5$ & $2082 \cdot 59^{a}$ & $723 \cdot 3$ & $1903 \cdot 29^{b}$ & $886 \cdot 6$ \\
\hline Total energy intake from fat (\%) & $38 \cdot 48^{a}$ & $5 \cdot 7$ & $36 \cdot 65^{b}$ & $6 \cdot 6$ & $38 \cdot 71^{\mathrm{a}}$ & $5 \cdot 5$ & $34 \cdot 90^{\mathrm{b}}$ & $7 \cdot 2$ \\
\hline
\end{tabular}

${ }^{\mathrm{a}, \mathrm{b}}$ Mean values within a row with unlike superscript letters were significantly different $(P<0.05)$.

among AA and HL women. The average fat intake was $35.77 \%$ of total daily energy intake, which exceeds national recommendations of $\leq 30 \%$ of total daily energy intake from fat ${ }^{(81)}$. Obesity status and diets high in fat pose significant risks for chronic diseases such as heart disease and diabetes ${ }^{(4-7)}$. Tailored interventions for AA and HL women are needed to improve diet and reduce weight status, thereby reducing risks for chronic diseases.

Results showed a marginally significant small interaction effect of neighbourhood FFR availability and binge eating on BMI, but no interaction effect on energy or fat intake. These results are consistent with a recent systematic review which concluded that the relationship between environment and BMI was more consistently demonstrated than the relationship between environment and diet ${ }^{(82)}$. The major limitation of assessing diet is that nearly all measures of diet are self-reported, thus the prevalence of reporting bias and errors is high ${ }^{(83,84)}$. Under-reporting has been shown to be particularly prevalent among female, obese and ethnic minority 
$\operatorname{adults}^{(83)}$, which includes the women in the present sample. Among bingers and obese non-bingers, underreporting has been shown to occur by as much as 20 to $33 \%{ }^{(85)}$. Social desirability contributes to underreporting ${ }^{(84)}$. For those who are ashamed of what or how much they eat (e.g. bingers), social desirability may lead to substantial under-reporting of dietary intake. Finally, dietary intake of foods eaten during binge episodes may not have been captured by the dietary assessment measure used in the present study (i.e. DHQ). Binge episodes may have been viewed as abnormal and excluded when asked to report 'usual' intakes over the last 12 months as instructed. Studies have shown that dietary intake varies widely between binge and non-binge days ${ }^{(85,86)}$. BMI measurements, while imperfect, are an objective measure with less variability due to reporting bias. Environmental associations based on BMI data may carry more validity than those based on dietary assessment data.

Results provide some evidence to suggest that the impact of neighbourhood FFR availability on BMI may depend on binge status; bingers with at least one neighbourhood FFR had higher BMI than bingers without neighbourhood FFR or non-bingers regardless of neighbourhood FFR. Among studies that have examined the association between neighbourhood FFR availability and $\mathrm{BMI}$, one has confirmed this relationship ${ }^{(30)}$. Results of the present study suggest that the moderating effect of binge eating may explain why the environment has an effect on weight status among some people but not everyone. Results are consistent with recent work from a Canadian group of researchers who showed that there was a stronger association between neighbourhood FFR availability and metabolic risk factors among individuals who had a low sense of control over their environment compared with individuals who had a strong sense of environmental control $^{(35)}$. Similarly, binge eating is characterized by loss of control over eating ${ }^{(38)}$. Additional research by the same Canadian group showed that there was a stronger association between neighbourhood FFR availability and fast-food consumption among individuals who were sensitive to external cues compared with those who were not ${ }^{(36)}$. Laboratory human and animal studies have shown that external cues promote binge eating and overeating in the absence of hunger among bingers but not among non-bingers ${ }^{(38)}$. FFR are often chain franchises with an easily recognizable and distinct store front associated with a specific standardized menu and flavour/ quality of highly palatable but unhealthy food ${ }^{(16,17)}$. Fastfood cravings have been related to greater frequency of eating out ${ }^{(87)}$. Among those prone to binge eat, learned associations between the features of FFR and the rewarding properties of fast food may lead to cravings and loss of control, resulting in overeating upon exposure to $\operatorname{FFR}^{(38)}$

Roughly one-third of the women in the present study were bingers. This is remarkable, as previous reports showed that $15-20 \%$ of a non-clinical multi-ethnic sample were bingers ${ }^{(39)}$. Bingers in the present sample had higher energy intake and higher fat intake than nonbingers but these effects were small. The literature suggests that diets among bingers and non-bingers differ depending on whether the measured day was a binge day or not. On binge days, bingers have greater energy and fat intakes than on non-binge days ${ }^{(85,86,88)}$. Binge frequencies vary but generally do not occur daily, except in the most extreme cases ${ }^{(89)}$. Energy and fat intakes do not differ significantly among obese non-bingers and bingers on non-binge days, but on binge days energy and fat intakes are significantly higher among bingers than obese non-bingers ${ }^{(85,88)}$. Compared with obese non-bingers, obese bingers consume more energy during a laboratory ad libitum eating episode ${ }^{(90)}$. In the current study, it is possible that the differences in energy and fat intakes between bingers and non-bingers were driven by binge and non-binge day differences in diet.

Strengths of the present study include a large diverse sample, meticulous and detailed objective measurement of neighbourhood food stores, and use of widely used validated measures of study variables. The BES was used to identify those who are prone to binge eating. Scores on this measure are correlated with binge eating disorder, but alone do not provide enough information for a definitive clinical diagnosis. Binge eating in the present study was merely one type of eating behaviour, not a diagnosis. The study sample represented healthy, middle-aged, overweight/obese women with moderate incomes who do not engage in physical activity regularly; therefore results are generalizable only to women who meet these criteria.

The present study has limitations worth noting. It was cross-sectional, which means that causality cannot be inferred from the results. AA women were more likely than HL women to under-report dietary intake data and drop out of the study early, so generalizability of the study's results is limited to those AA women who are likely to participate in a diet and physical activity intervention study (i.e. the parent study). The small sample size may have reduced the ability to detect true interaction effects. While the DHQ is widely used among minority populations and it was validated on diverse samples, the validation samples contained a larger proportion of whites than any other racial/ethnic background. Also, the DHQ could be considered a type of FFQ, which has been shown to have slightly poorer reliability and validity than other dietary assessment methods like $24 \mathrm{~h}$ dietary recalls when compared with biomarkers of dietary intake and energy expenditure (e.g. doubly labelled water) ${ }^{(83,91,92)}$. Benefits of FFQ are that they are far more cost-effective and feasible than $24 \mathrm{~h}$ dietary recalls and far less burdensome on participants than food diaries. For these reasons, they are still widely used in public health research including national surveillance systems (Behavioral Risk Factor Surveillance System). 
Existing dietary assessment methods may be particularly problematic for bingers; therefore research may be needed to develop dietary assessment measures specifically for bingers to address binge and non-binge day variations. Bingers in the present sample had higher energy intake and higher fat intake than non-bingers but these effects were small. It is likely that differences in diet on binge days $v$. non-binge days may be driving the differences in diet between bingers and non-bingers. Future research should determine whether reducing binge frequency without necessarily addressing diet composition would reduce overall intakes of energy and fat among bingers.

\section{Conclusion}

High-fat diets and binge eating were common among the AA and HL women in the present sample. These results demonstrate the need for tailored interventions for AA and HL women to reduce energy and fat intakes and BMI. The influence of neighbourhood FFR availability on BMI depended on binge status; bingers with at least one neighbourhood FFR had higher BMI than bingers with no neighbourhood FFR or non-bingers regardless of neighbourhood FFR availability. These results provide some insight into why some but not all individuals may be prone to obesity and overeating in an environment with high availability of FFR. Future research should continue to identify the features of FFR that may promote binge eating among bingers, and also identify additional individual factors that may make some more sensitive to obesity and overeating in response to obesogenic environmental conditions. Additional research should also identify other environmental factors bingers may be sensitive to. Results of these studies would be useful in informing policies to reduce obesogenic features of the environment and also to inform individual-level treatments for obese individuals with binge eating tendencies (e.g. coping with FFR).

\section{Acknowledgements}

Sources of funding: This work was supported by the Health is Power study funded by grant 1R01CA109403 from the National Institutes of Health (NIH), National Cancer Institute (NCI) awarded to R.E.L. at the University of Houston. The NIH and NCI had no role in the design, analysis or writing of this article. Conflicts of interest: There are no conflicts of interest to report. Authors' contributions: T.L. designed the study, conducted analyses and prepared the manuscript; H.A.-L. prepared portions of the manuscript and reviewed drafts of the manuscript; D.P.O. conducted statistical analyses, assisted with the study design and reviewed drafts of the manuscript; S.M. was Project Coordinator on the parent study, facilitated data collection and prepared portions of the manuscript; R.E.L. was Principal Investigator on the parent study, designed the parent study, reviewed drafts of the manuscript and supplied the data. Each author has seen and approved the contents of the submitted manuscript.

\section{References}

1. Davis AM, Vinci LM, Okwuosa TM et al. (2007) Cardiovascular health disparities: a systematic review of health care interventions. Med Care Res Rev 64, 5 Suppl., 29S-100S.

2. Flegal KM, Carroll MD, Ogden CL et al. (2010) Prevalence and trends in obesity among US adults, 1999-2008. JAMA 303, 235-241.

3. Peek ME, Cargill A, Huang ES et al. (2007) Diabetes health disparities: a systematic review of health care interventions. Med Care Res Rev 64, 5 Suppl., 101S-156S.

4. Mente A, de Koning L, Shannon HS et al. (2009) A systematic review of the evidence supporting a causal link between dietary factors and coronary heart disease. Arch Intern Med 169, 659-669.

5. Lichtenstein AH, Kennedy E, Barrier P et al. (1998) Dietary fat consumption and health. Nutr Rev 56, 5 Pt 2, S3-S19.

6. Kuller LH (1997) Dietary fat and chronic diseases: epidemiologic overview. J Am Diet Assoc 97, 7 Suppl., S9-S15.

7. Kirkpatrick SI, Dodd KW, Reedy J et al. (2012) Income and race/ethnicity are associated with adherence to food-based dietary guidance among US adults and children. $J$ Acad Nutr Diet 112, 624-635.e6.

8. Lee RE, McAlexander KM Banda JA et al. (2011) Reversing the Obesogenic Environment. Champaign, IL: Human Kinetics.

9. Frank L, Kerr J, Saelens B et al. (2009) Food outlet visits, physical activity and body weight: variations by gender and race-ethnicity. Br J Sports Med 43, 124-131.

10. Sallis JF \& Glanz K (2009) Physical activity and food environments: solutions to the obesity epidemic. Milbank $Q \mathbf{8 7}, 123-154$.

11. Spence J \& Lee RE (2003) Toward a comprehensive model of physical activity. Psychol Sport Exerc 4, 7-24.

12. Larson NI, Story MT, Nelson MC et al. (2009) Neighborhood environments: disparities in access to healthy foods in the US. Am J Prev Med 36, 74-81.

13. Baker EA, Schootman M, Barnidge E et al. (2006) The role of race and poverty in access to foods that enable individuals to adhere to dietary guidelines. Prev Chronic Dis 3, A76.

14. Kestens Y \& Daniel M (2010) Social inequalities in food exposure around schools in an urban area. Am J Prev Med 39, 33-40.

15. Azuma AM, Gilliland S, Vallianatos M et al. (2010) Food access, availability, and affordability in 3 Los Angeles communities, Project CAFE, 2004-2006. Prev Chronic Dis 7, A27.

16. Prentice AM \& Jebb SA (2003) Fast foods, energy density and obesity: a possible mechanistic link. Obes Rev 4, 187-194.

17. Lin B, Frazao E, Guthrie J et al. (1999) Away-From-Home Foods Increasingly Important to Quality of American Diet. Agriculture Information Bulletin no. AIB-749. Washington, DC: US Department of Agriculture, Economic Research Service.

18. Satia JA, Galanko JA, Siega-Riz AM et al. (2004) Eating at fast-food restaurants is associated with dietary intake, demographic, psychosocial and behavioural factors among African Americans in North Carolina. Public Health Nutr 7 , 1089-1096. 
19. French SA, Story M, Jeffery RW et al. (2001) Environmental influences on eating and physical activity. Annu Rev Public Health 22, 309-335.

20. Bowman SA \& Vinyard BT (2004) Fast food consumption of US adults: impact on energy and nutrient intakes and overweight status. J Am Coll Nutr 23, 163-168.

21. Pereira MA, Kartashov AI, Ebbeling CB et al. (2005) Fastfood habits, weight gain, and insulin resistance (the CARDIA study): 15-year prospective analysis. Lancet $\mathbf{3 6 5}$, 36-42.

22. Jeffery RW, Baxter J, McGuire M et al. (2006) Are fast food restaurants an environmental risk factor for obesity? Int $J$ Behav Nutr Phys Act 3, 2.

23. Li F, Harmer P, Cardinal BJ et al. (2009) Obesity and the built environment: does the density of neighborhood fast-food outlets matter? Am J Health Promot 23, 203-209.

24. Mehta NK \& Chang VW (2008) Weight status and restaurant availability a multilevel analysis. Am J Prev Med 34, 127-133.

25. Sharkey JR, Johnson CM, Dean WR et al. (2011) Association between proximity to and coverage of traditional fast-food restaurants and non-traditional fast-food outlets and fastfood consumption among rural adults. Int J Health Geogr $10,37$.

26. Sharkey JR, Johnson CM, Dean WR et al. (2011) Focusing on fast food restaurants alone underestimates the relationship between neighborhood deprivation and exposure to fast food in a large rural area. Nutr J 10, 10.

27. Boone-Heinonen J, Gordon-Larsen P, Kiefe CI et al. (2011) Fast food restaurants and food stores: longitudinal associations with diet in young to middle-aged adults: the CARDIA study. Arch Intern Med 171, 1162-1170.

28. Giskes K, Avendano M, Brug J et al. (2010) A systematic review of studies on socioeconomic inequalities in dietary intakes associated with weight gain and overweight/obesity conducted among European adults. Obes Rev 11, 413-429.

29. Morland K, Wing S, Diez Roux A et al. (2002) The contextual effect of the local food environment on residents' diets: the atherosclerosis risk in communities study. Am J Public Health 92, 1761-1767.

30. Fleischhacker SE, Evenson KR, Rodriguez DA et al. (2011) A systematic review of fast food access studies. Obes Rev 12, e460-e471.

31. Richardson AS, Boone-Heinonen J, Popkin BM et al. (2011) Neighborhood fast food restaurants and fast food consumption: a national study. BMC Public Health 11, 543.

32. Pearce J, Hiscock R, Blakely T et al. (2009) A national study of the association between neighbourhood access to fastfood outlets and the diet and weight of local residents. Health Place 15, 193-197.

33. Zenk SN, Schulz AJ, Matthews SA et al. (2011) Activity space environment and dietary and physical activity behaviors: a pilot study. Health Place 17, 1150-1161.

34. Kestens Y, Lebel A, Chaix B et al. (2012) Association between activity space exposure to food establishments and individual risk of overweight. PLoS One 7, e41418.

35. Paquet C, Dube L, Gauvin L et al. (2010) Sense of mastery and metabolic risk: moderating role of the local fast-food environment. Psychosom Med 72, 324-331.

36. Paquet C, Daniel M, Knauper B et al. (2010) Interactive effects of reward sensitivity and residential fast-food restaurant exposure on fast-food consumption. Am J Clin Nutr 91, 771-776.

37. Bulik CM, Brownley KA, Shapiro JR et al. (2007) Diagnosis and management of binge eating disorder. World Psychia$\operatorname{try} 6,142-148$.

38. Mathes WF, Brownley KA, Mo X et al. (2009) The biology of binge eating. Appetite 52, 545-553.

39. Regan PC \& Cachelin FM (2006) Binge eating and purging in a multi-ethnic community sample. Int J Eat Disord 39, 523-526.
40. Sobik L, Hutchison K, Craighead L et al. (2005) Cue-elicited craving for food: a fresh approach to the study of binge eating. Appetite 44, 253-261.

41. Staiger P, Dawe S, McCarthy R et al. (2000) Responsivity to food cues in bulimic women and controls. Appetite 35, $27-33$.

42. Wardle J (1990) Conditioning processes and cue exposure in the modification of excessive eating. Addict Behav 15, 387-393.

43. de Zwaan M (2001) Binge eating disorder and obesity. Int J Obes Relat Metab Disord 25, Suppl. 1, S51-S55.

44. de Zwaan M, Mitchell JE, Raymond NC et al. (1994) Binge eating disorder: clinical features and treatment of a new diagnosis. Harv Rev Psychiatry 1, 310-325.

45. Abraham SF \& Beumont PJ (1982) How patients describe bulimia or binge eating. Psychol Med 12, 625-635.

46. Smyth JM, Wonderlich SA, Sliwinski MJ et al. (2009) Ecological momentary assessment of affect, stress, and binge-purge behaviors: day of week and time of day effects in the natural environment. Int J Eat Disord 42, 429-436.

47. Waters A, Hill A, Waller G et al. (2000) Internal and external antecedents of binge eating episodes in a group of women with bulimia nervosa. Int J Eat Disord 29, 17-22.

48. Glass J, Mitchell JE, de Zwaan M et al. (2004) Eating behavior and other distracting behaviors while driving among patients with eating disorders. Compr Psychiatry 45, 235-237.

49. Lee RE, Medina AV, Mama SK et al. (2011) Health is Power: an ecological, theory-based health intervention for women of color. Contemp Clin Trials 32, 916-923.

50. Lee RE, Mama SK, Medina AV et al. (2011) Multiple measures of physical activity, dietary habits and weight status in African American and Hispanic or Latina women. J Community Health 36, 1011-1023.

51. Lee RE, Mama SK, McAlexander KP et al. (2011) Neighborhood and PA: neighborhood factors and physical activity in African American public housing residents. $J$ Phys Act Health 8, Suppl. 1, S83-S90.

52. Lee RE, O'Connor DP, Smith-Ray R et al. (2012) Mediating effects of group cohesion on physical activity and diet in women of color: health is power. Am J Health Promot 26, e116-e125.

53. Smith-Ray R, Mama SK, Reese-Smith J et al. (2012) Improving participation rates for women of color in health research: the role of group cohesion. Prev Sci 13, 27-35.

54. Kueht ML, McFarlin BK Lee RE et al. (2009) Severely obese have greater LPS-stimulated TNF- $\alpha$ production than normal weight African-American women. Obesity (Silver Spring) 17, 447-451.

55. Layne CS, Mama SK, Banda JA et al. (2011) Development of an ecologically valid approach to assess moderate physical activity using accelerometry in community dwelling women of color: a cross-sectional study. Int J Behav Nutr Phys Act 8, 21.

56. McAlexander KM, Mama SK, Medina A et al. (2011) The concordance of directly and indirectly measured built environment attributes and physical activity adoption. Int J Behav Nutr Phys Act 8, 72.

57. Mama SK, Quill BE, Fernandz-Esquer ME et al. (2011) Body image and physical activity among African American and Hispanic or Latina women. Ethn Dis 21, 281-287.

58. Lee RE, Booth KM, Reese-Smith JY et al. (2005) The Physical Activity Resource Assessment (PARA) instrument: evaluating features, amenities and incivilities of physical activity resources in urban neighborhoods. Int J Behav Nutr Phys Act 2, 13.

59. Parmenter BM, McMillan T, Cubbin C et al. (2008) Developing geospatial data management, recruitment, and analysis techniques for physical activity research. Urban Regional Inform Syst Assoc J 20, 13-19. 
60. Lee RE, Heinrich KM, Medina AV et al. (2010) A picture of the healthful food environment in two diverse urban cities. Environ Health Insights 4, 49-60.

61. Sarnoff R \& Hughes D (2005) Increasing health insurance coverage in the first year of life. Matern Child Health J 9, 343-350.

62. Gormally J, Black S, Daston S et al. (1982) The assessment of binge eating severity among obese persons. Addict Behav 7, 47-55.

63. Timmerman GM (1998) Caloric intake patterns of nonpurge binge-eating women. West J Nurs Res 20, 103-118.

64. Timmerman G (1999) Binge eating scale: further assessment of validity and reliability. J Appl Behav Res 4, 1-12.

65. Harrington EF, Crowther JH, Henrickson HC et al. (2006) The relationships among trauma, stress, ethnicity, and binge eating. Cultur Divers Ethnic Minor Psychol 12, 212-229.

66. Mitchell KS \& Mazzeo SE (2004) Binge eating and psychological distress in ethnically diverse undergraduate men and women. Eat Behav 5, 157-169.

67. Grupski AE, Hood MM, Hall BJ et al. (2013) Examining the Binge Eating Scale in screening for binge eating disorder in bariatric surgery candidates. Obes Surg 23, 1-6.

68. Meneghini LF, Spadola J, Florez H et al. (2006) Prevalence and associations of binge eating disorder in a multiethnic population with type 2 diabetes. Diabetes Care 29, 2760.

69. Azarbad L, Corsica J, Hall B et al. (2010) Psychosocial correlates of binge eating in Hispanic, African American, and Caucasian women presenting for bariatric surgery. Eat Behav 11, 79-84.

70. Goodrick GK, Poston WS 2nd, Kimball KT et al. (1998) Nondieting versus dieting treatment for overweight bingeeating women. J Consult Clin Psychol 66, 363-368.

71. Marcus MD, Wing RR \& Hopkins J (1988) Obese bingers: affect, cognitions, and response to behavioural weight control. J Consult Clin Psychol 56, 433-439.

72. Subar AF, Thompson FE, Smith AF et al. (1995) Improving food frequency questionnaires: a qualitative approach using cognitive interviewing. J Am Diet Assoc 95, 781-788.

73. Subar AF, Thompson FE, Kipnis V et al. (2001) Comparative validation of the Block, Willett, and National Cancer Institute food frequency questionnaires: the Eating at America's Table Study. Am J Epidemiol 154, 1089-1099.

74. Subar AF, Ziegler RG, Thompson FE et al. (2001) Is shorter always better? Relative importance of questionnaire length and cognitive ease on response rates and data quality for two dietary questionnaires. Am J Epidemiol 153, 404-409.

75. Williams CD, Satia JA, Adair LS et al. (2009) Dietary patterns, food groups, and rectal cancer risk in Whites and African-Americans. Cancer Epidemiol Biomarkers Prev 18, $1552-1561$.

76. Tabung F, Steck SE, Su LJ et al. (2012) Intake of grains and dietary fiber and prostate cancer aggressiveness by race. Prostate Cancer 2012, 323296.

77. Scialla JJ, Appel LJ, Wolf M et al. (2012) Plant protein intake is associated with fibroblast growth factor 23 and serum bicarbonate levels in patients with chronic kidney disease: the Chronic Renal Insufficiency Cohort study. J Ren Nutr 22, 379-388.e1.
78. George SM, Thompson FE, Midthune D et al. (2012) Strength of the relationships between three self-reported dietary intake instruments and serum carotenoids: the Observing Energy and Protein Nutrition (OPEN) Study. Public Health Nutr 15, 1000-1007.

79. Ledoux TA, Mama SK, O'Connor DP et al. (2012) Home availability and the impact of weekly stressful events are associated with fruit and vegetable intake among African American and Hispanic/Latina women. J Obes 2012, 737891.

80. Adamus H, Lopez Y, Das S et al. (2014) A comprehensive analysis of objective measures of environmental support for physical activity and healthful eating. Am J Health Promot (In the Press).

81. US Department of Health and Human Services, US Department of Agriculture \& US Dietary Guidelines Advisory Committee (2010) Dietary Guidelines for Americans, 2010. Washington, DC: Government Printing Office.

82. Giskes K, Van Lenthe F, Avendano-Pabon M et al. (2011) A systematic review of environmental factors and obesogenic dietary intakes among adults: are we getting closer to understanding obesogenic environments? Obes Rev 12, e95-e106.

83. Livingstone MB \& Black AE (2003) Markers of the validity of reported energy intake. J Nutr 133, Suppl. 3, 895S-920S.

84. Klesges LM, Baranowski T, Beech B et al. (2004) Social desirability bias in self-reported dietary, physical activity and weight concerns measures in 8- to 10-year-old AfricanAmerican girls: results from the Girls Health Enrichment Multisite Studies (GEMS). Prev Med 38, Suppl., S78-S87.

85. Raymond NC, Peterson RE, Bartholome LT et al. (2012) Comparisons of energy intake and energy expenditure in overweight and obese women with and without binge eating disorder. Obesity (Silver Spring) 20, 765-772.

86. Reeves RS, McPherson RS, Nichaman MZ et al. (2001) Nutrient intake of obese female bingers. J Am Diet Assoc 101, 209-215.

87. Siwik VP \& Senf JH (2006) Food cravings, ethnicity and other factors related to eating out. J Am Coll Nutr 25, 382-388.

88. Raymond NC, Neumeyer B, Warren CS et al. (2003) Energy intake patterns in obese women with binge eating disorder. Obes Res 11, 869-879.

89. Allison S \& Timmerman GM (2007) Anatomy of a binge: food environment and characteristics of nonpurge binge episodes. Eat Behav 8, 31-38.

90. Raymond NC, Bartholome LT, Lee SS et al. (2007) A comparison of energy intake and food selection during laboratory binge eating episodes in obese women with and without a binge eating disorder diagnosis. Int J Eat Disord 40, 67-71.

91. Subar AF, Kipnis V, Troiano RP et al. (2003) Using intake biomarkers to evaluate the extent of dietary misreporting in a large sample of adults: the OPEN study. Am J Epidemiol 158, $1-13$

92. Trabulsi J \& Schoeller DA (2001) Evaluation of dietary assessment instruments against doubly labeled water, a biomarker of habitual energy intake. Am J Physiol Endocrinol Metab 281, e891-e899. 